\title{
O Uso de Objetos de Aprendizagem na Educação Financeira: Metodologia para Avaliação Pautada nos Aspectos Tecnológicos e Pedagógicos
}

\section{Gisele Barbosa}

Universidade Federal de Juiz de Fora/UFJF

Núcleo de Investigação, Divulgação e Estudos em Educação Matemática

barbosagisa@yahoo.com.br

\section{Liamara Scortegagna}

Universidade Federal de Juiz de Fora/UFJF

Departamento de Ciência da Computação

liamara@ice.ufjf.br

\section{Resumo}

A utilização de recursos digitais como os Objetos de Aprendizagem (OA) no ensino da Educação Financeira Escolar, visa incentivar e aproximar o aluno do conteúdo, tornando a complexa arte de ensinar em um ato atrativo e interativo. Porém, o desconhecimento e a dificuldade de busca, seleção e avaliação destes recursos por parte dos professores, desestimula a utilização em sala de aula. A pesquisa apresentada neste artigo objetiva auxiliar o professor e propõe uma Metodologia para Avaliação de Objetos de Aprendizagem (MESA), pautada nos aspectos tecnológicos e pedagógicos. Para isso, utilizamos uma metodologia de pesquisa bibliográfica e exploratória pautados em leituras e análises de exemplos de OA. Como resultado, observamos a pluralidade dos aspectos mencionados para caracterizar os $\mathrm{OA}$, o número reduzido de $\mathrm{OA}$ na área de Educação Financeira e a dificuldade de busca nos repositórios. Concluímos ainda, que os OA apresentam um importante potencial pedagógico para o ensino da Educação Financeira Escolar.

Palavras-chave: Educação matemática. Objetos de aprendizagem. Recurso educacional. Educação financeira escolar.

\section{The Use of Learning Objects in Financial Education: Methodology for Guided Assessment in Technological and Educational Aspects}

\begin{abstract}
The use of digital resources such as Learning Objects in the teaching of Financial Education school, aims to encourage and make the student closer to the content, making the complex art of teaching in an attractive and interactive act. However, the miss of knowledge of the subject and also the difficulties for search, selection and evaluation of these resourses by teachers, discourages the use in the classroom. The research presented in this paper aims to help teachers and propose a Methodology for Learning Object Evaluation, based on technological and pedagogical aspects. For this, we used the methodology of bibliography and exploratory research guided in readings and analysis of examples of Learning Objects. Our results indicate the plurality of aspects mentioned to characterize the Learning Objects, the reduced number of Learning Objects in Financial Education
\end{abstract}


and the search for difficulties in the repositories. However, we concluded that Learning Objects provides important pedagogical potential for teaching Financial Education.

Keywords: Mathematics Education. Learning Objects. Educational Resource. School Financial Education.

\section{Introdução}

A pesquisa que apresentaremos nesse artigo e parte de um projeto de pesquisa maior intitulado Design e Desenvolvimento de um Programa de Educação Financeira para a Formação de Estudantes e Professores da Educação Básica, desenvolvida no Núcleo de Investigação, Divulgação e Estudos em Educação Matemática e no Programa de Pós-Graduação em Educação Matemática da UFJF e cuja proposta caracteriza-se como um projeto de pesquisa e desenvolvimento em Educação Matemática e têm como meta reforçar as ações brasileiras de inserção do tema Educação Financeira nas escolas públicas, em atendimento as recomendações da Organização para Cooperação e Desenvolvimento Econômico (OCDE).

Nossa parte nesse projeto tinha como objetivo desenvolver uma metodologia para avaliação de Objetos de Aprendizagem, pautada nos aspectos tecnológicos e pedagógicos.

Inicialmente, para situar nossa pesquisa, observamos que neste artigo, ferramentas didáticas de suporte ao professor são consideradas como um recurso educacional e, a partir de definições pesquisadas, assumimos os Objetos de Aprendizagem (OA) como recursos educacionais, suportados pelas tecnologias, que integram múltiplos mecanismos de informação interativa como áudio, vídeo ou texto. Além disso, caracteriza-se pela disponibilização de um determinado conteúdo educacional disciplinar em pequenos trechos e pela possibilidade de reutilização em vários ambientes de aprendizagem.

Devido aos atributos pedagógicos presentes nos OA, é possível estimular nos alunos diferentes procedimentos cognitivos como a observação, a comparação, a análise, a elaboração de hipóteses, a memorização, a checagem ou a manipulação de dados.

Outro aspecto importante é a possibilidade de sua reutilização e sua adequação sem perda de características, em cursos presenciais ou à distância, além da opção de utilização pelo aluno em horário não escolar. Em termos técnicos os $\mathrm{OA}$ são compatíveis com diversas plataformas e, geralmente, elaborados com vários elementos gráficos ou disponibilizados em hiperlinks, permitindo maior interação entre o usuário e o OA.

A importância deste trabalho se respalda no fato dos professores, usuários destes objetos educacionais para Educação Matemática, por vezes, encontrarem dificuldades para decidir entre os 
OA mais adequados para sua utilização. Verificamos também, um número pequeno de investigações sobre avaliação dos OA quanto às suas funcionalidades pedagógicas. Além disso, essa pesquisa se legitima por oportunizar a discussão de características relevantes para a utilização desses recursos educacionais.

A proposta de uma metodologia de avaliação de OA para o ensino da Educação Financeira Escolar objetiva ainda, servir de direcionamento para o desenvolvimento de outros materiais didáticos, cujo objetivo seja, por exemplo, o desenvolvimento de tarefas e atividades em sala de aula ou fora dela.

A metodologia de pesquisa empregada classifica-se como qualitativa, exploratória e descritiva. Nossas fontes de dados incidiram em levantamento bibliográfico, pesquisas em repositórios educacionais e análise de exemplos de OA.

$\mathrm{Na}$ seção seguinte apresentaremos uma descrição sobre as conceituações de OA, o significado de metadados e padronização, ilustrando sua importância e utilização, bem como, apresentamos alguns exemplos de repositórios responsáveis pelo armazenamento destes. Focaremos nas características e alguns processos de avaliação comumente utilizados para os recursos digitais.

\section{Objetos de Aprendizagem (OA): Metadados, Padronização e Armazenamento}

Os OA são alvo de pesquisas há mais de duas décadas, por estudiosos como Krämer e Schimidt (2001), L'Allier (1997), Porter (2001) e Wiley (2000). Esses autores relacionam os OA à divisão de um assunto em pequenos módulos instrucionais, para fins de ensino e aprendizagem. A partir dessas "quebras" ou "partições" de um conteúdo, elaboram-se, de maneira contextualizada, atividades de simulação, animação ou uma explicação conceitual mais detalhada e ilustrada. Contudo, de acordo com tais autores, deve-se ter o cuidado de que esses OA sejam desenvolvidos em formato que permita sua reutilização por diferentes usuários e contextos, tanto de forma isolada, quanto combinada a outros OA.

Segundo Wiley (2009), a ideia de objetos de aprendizagem não é nova e seu início foi atribuído à Gerard, em 1969, quando ele falava sobre pequenos modulares, componentes instrucionais reusáveis e de unidades curriculares, as quais poderiam ser estruturadas em pequenas e combináveis partes.

No entanto, a concepção dos OA se popularizou em 1992, quando Wayne Hodgins utilizou uma explícita comparação deles com o brinquedo LEGO das crianças. Nessa comparação, os OA são entendidos como as peças desse brinquedo infantil, as quais podem ser empilhadas para compor uma nova peça ou remodelada para formar um novo objeto. Essa metáfora, apesar de criticada por 
Wiley (2000), devido à sua não adequação à compreensão ampla da proposta dos OA, ainda hoje é referenciada em pesquisas como a de Tarouco (2012).

Os metadados são definidos como descritores dos atributos que servem para catalogar um OA (TAROUCO (2012). Catalogar, significa atribuir informações que identifiquem o OA, tais como seu autor, palavras-chave, assunto, versão, localização, tipo de mídia, nível de interatividade, dentre outras.

Logo, metadados são, literalmente dados sobre dados, ou informações que se atribuem ao OA a fim de que seja possível sua localização e recuperação. Como enfatiza Wiley (2000), eles expõem detalhes acerca do OA.

Alguns órgãos internacionais e instituições brasileiras têm se ocupado na criação de um subconjunto uniforme de metadados ou campos obrigatórios, a serem preenchidos no momento de finalização de um OA.

Segundo Silva (2011), o padrão de metadados mais antigo e que serviu de referência para muitos outros é o LOM. Ele foi proposto pelo Instituteof Eletrical and Electronics Engineers (IEEE) em 2002. Já o padrão de metadados SCORM é outra proposta que, embora se baseie no LOM “é o padrão mais utilizado pelos profissionais e empresas que produzem OA" (p.32). O padrão brasileiro de metadados OBAA foi desenvolvido por uma equipe de pesquisadores da Universidade Federal do Rio Grande do Sul em 2009 e se baseou principalmente nas especificações do IEEE.

Dá-se o nome de Repositório de Objetos de Aprendizagem (ROA) aos bancos de dados online que armazenam os OA e recursos digitais. Harman e Koohang (2007) os definem como um catálogo online para auxiliar na pesquisa desses materiais, uma vez que em sistemas de busca usuais da Internet, nem sempre é possível localizá-los, devido a informações insuficientes ou imprecisas de ordem técnica.

Considerando a reutilização como uma importante característica dos $\mathrm{OA}$, sua conservação em repositórios é uma maneira confiável para futuro reuso. Esses bancos, em sua maioria, operam com um padrão de indexação, ou seja, padroniza-se a descrição dos conteúdos dos objetos, quando catalogados e armazenados, no intuito de possibilitar a recuperação em pesquisa de busca dos mesmos, por isso, a importância de se padronizar os metadados dos OA, visto que isso torna mais fácil sua inclusão nos repositórios, que operarão com as mesmas atribuições dos descritores desses materiais.

Segundo Tarouco (2012), tais repositórios devem permitir as funcionalidades de armazenamento dos objetos, controle de versões e de publicação. Também, que se busquem os objetos a partir de suas características expressas, mediante o uso de metadados, controle de acesso e 
a avaliação dos objetos. A autora acrescenta que poderá estar disponível no repositório o próprio material catalogado ou apenas informações sobre o endereço do conteúdo.

A fim de ilustrarmos, apresentamos como exemplos de repositórios o $\operatorname{RIVED}^{l}$, o PROATIVA $^{2}$, o CESTA $^{3}$, o Banco Internacional de Objetos Educacionais (BIOE) ${ }^{4}$ e o Multimedia Educational Resources for Learning and Online Teaching (MERLOT) ${ }^{5}$.

\section{Características dos AO: Aspectos Tecnológicos e Pedagógicos}

Os trabalhos e pesquisas sobre o desenvolvimento e utilização de OA têm nos proporcionado algumas compreensões. Uma delas é que a grande quantidade das pesquisas existentes nesta área e as diversas conceituações atribuídas ao OA dificultam uma unânime caracterização sobre esses objetos. Também, conforme Macedo (2010) salienta, há falta de consenso em relação ao termo OA.

Por outro lado, há concordância entre os estudiosos de que os OA devem ter um propósito educacional estabelecido, um componente que estimule a reflexão do estudante e que tenha sido desenvolvido de maneira a serem facilmente reutilizados noutros contextos de ensino e aprendizagem.

Assim, objetivamos uma análise mais detalhada dessas características em relação aos aspectos tecnológicos e pedagógicos, os quais são assinalados por diferentes estudiosos desse assunto.

Em relação às características gerais dos OA, Wiley (2000) destaca alguns requisitos como, a reusabilidade, a utilização em diferentes contextos de aprendizagem, possibilidade de compartilhamento simultaneamente e em qualquer lugar a partir da Internet. Além da possibilidade dos usuários contribuírem para a melhoria dos objetos.

No entanto, de acordo com Menezes et al. (2006), uma das vertentes de pesquisas ligada ao assunto objetos virtuais de aprendizagem gira em torno de questões técnicas. Possivelmente devido à sua natureza e surgimento na informática, tais discussões, também comentados em Jesus et al. (2012), estão diretamente associadas à construção, armazenamento, catalogação e indexação de um objeto de aprendizagem.

Do ponto de vista tecnológico, desde seu desenvolvimento até sua versão final disponibilizada, pesquisadores discutem como classificar, armazenar, recuperar, transmitir e reutilizar um OA. Além disso, preocupações com padronizações, sugestões de formatação e

\footnotetext{
${ }^{1}$ Disponível em:<http://rived.mec.gov.br/site_objeto_lis.php>. Acesso em 29/13/15.

${ }^{2}$ Disponível em: $<$ http://www.proativa.vdl.ufc.br/>.Acesso em 20/11/13.

${ }^{3}$ Disponível em:<http://www.cinted.ufrgs.br/CESTA/>.Acesso em 29/03/15.

${ }^{4}$ Disponível em: $<$ http://objetoseducacionais2.mec.gov.br/ $>>$. Acesso em 29/03/15.

${ }^{5}$ Disponível em:<http://www.merlot.org/merlot/index.htm>. Acesso em 29/03/15.
} 
recomendações a serem observadas no momento de seu desenvolvimento. Ocupar-se dessas questões contribuem para um uso eficaz destes recursos educacionais.

Com o intuito de que os OA possam ser utilizados e reutilizados, agrupados e reagrupados, observamos as tendências nos diversos trabalhos acadêmicos, quanto às principais características que os OA apresentam em relação aos aspectos tecnológicos, conforme descrito na tabela 1 abaixo.

Tabela 1 - Aspectos Tecnológicos dos Objetos de Aprendizagem

\begin{tabular}{|c|c|c|}
\hline \multicolumn{3}{|c|}{ Aspectos Tecnológicos Pesquisados } \\
\hline Característica & Definição & Autor/Fonte \\
\hline $\begin{array}{l}\text { Interoperabilidade } \\
\text { Portabilidade } \\
\text { Durabilidade } \\
\text { Adaptabilidade } \\
\text { Flexibilidade }\end{array}$ & $\begin{array}{l}\text { A possibilidade de serem utilizados em diferentes } \\
\text { ambientes de ensino, plataformas, sistema operacional } \\
\text { e navegador web, não necessitando para isso, sofrer } \\
\text { recodificação. É a não obsolescência do OA quando a } \\
\text { base tecnológica muda. }\end{array}$ & $\begin{array}{l}\text { Simone (2006); Carvalho } \\
\text { (2008); Santaché et al. (2008); } \\
\text { Polsani (2003); De Bettio e } \\
\text { Martins (2004); Tarouco et al. } \\
\text { (2003); Torrão (2008); Flôres et } \\
\text { al. (2009) e IEEE (2002) }\end{array}$ \\
\hline $\begin{array}{l}\text { Reutilização ou } \\
\text { Reusabilidade }\end{array}$ & $\begin{array}{l}\text { Capacidade de ser reaproveitado em diferentes } \\
\text { contextos de aprendizagem, sem necessidade de ser } \\
\text { redesenhado de modo a enquadrar-se no novo } \\
\text { contexto. Varia de acordo com a Granularidade do } \\
\text { OA. }\end{array}$ & $\begin{array}{l}\text { Simone (2006); Carvalho } \\
\text { (2008); Wiley (200); Moreno } \\
\text { (2002); Cisco (1999); Torrão } \\
\text { (2008) e De Bettio e Martins } \\
\text { (2004) }\end{array}$ \\
\hline $\begin{array}{l}\text { Recuperabilidade } \\
\text { Acessibilidade: } \\
\text { disponibilidade }\end{array}$ & $\begin{array}{l}\text { Está ligado ao fato dos objetos de aprendizagem ser } \\
\text { identificados pelos "metadados", os quais os tornam } \\
\text { localizáveis, mesmo em lugares remotos. É a } \\
\text { facilidade de acesso pelos mecanismos de busca. }\end{array}$ & $\begin{array}{l}\text { Simone (2006); Carvalho } \\
\text { (2008); Gomes et al. (2004); } \\
\text { Polsani (2003); Tarouco et al. } \\
\text { (2003) e Torrão (2008) }\end{array}$ \\
\hline $\begin{array}{l}\text { Acessibilidade: } \\
\text { minimizar barreiras } \\
\text { arquitetônicas }\end{array}$ & $\begin{array}{l}\text { Implica na possibilidade de utilização por pessoas } \\
\text { com necessidades especiais, decorrentes de limitações } \\
\text { sensório-motoras. }\end{array}$ & $\begin{array}{l}\text { Simone (2006); Carvalho } \\
\text { (2008); IEEE/LTSC (2000); } \\
\text { Polsani (2003); Tarouco et al. } \\
\text { (2003) e Torrão (2008) }\end{array}$ \\
\hline Escalabilidade & $\begin{array}{l}\text { A facilidade de poder ser utilizado com pequeno ou } \\
\text { grande número de usuários. }\end{array}$ & $\begin{array}{l}\text { Carvalho, J. (2008) e Torrão } \\
\text { (2008) }\end{array}$ \\
\hline $\begin{array}{l}\text { Indexação } \\
\text { Classificação } \\
\text { Metadados } \\
\text { Padronização }\end{array}$ & $\begin{array}{l}\text { Permissão de atribuição de índices ou a catalogação, } \\
\text { os quais facilitarão a localização e identificação do } \\
\text { objeto nos mecanismos de busca. }\end{array}$ & $\begin{array}{l}\text { IEEE/LTSC (2000); Sphepherd } \\
\text { (2000); Filatro (2008); De } \\
\text { Bettio e Martins (2004); } \\
\text { Carvalho, (2008); Simone } \\
\text { (2006); } \\
\text { Wiley (2000) e Moreno (2002) }\end{array}$ \\
\hline $\begin{array}{l}\text { Granularidade } \\
\text { Nível de agregação } \\
\text { Customização }\end{array}$ & $\begin{array}{l}\text { É a capacidade do objeto de aprendizagem poder ser } \\
\text { agrupado e reagrupado em conjuntos maiores de } \\
\text { conteúdos, sendo usado em um curso ou outro da } \\
\text { maneira que mais convier. Isso dependerá da } \\
\text { granularidade. Quanto mais granular um OA for, } \\
\text { maior sua capacidade de reutilização e nível de } \\
\text { agregação. Gerando, com isso maior customização } \\
\text { desses OA ao facilitar sua adaptação ou junção a } \\
\text { outros OA. }\end{array}$ & $\begin{array}{c}\text { Simone (2006); Verbet(2008); } \\
\text { Santaché et al. (2008); Polsani } \\
\text { (2003); Torrão (2008); Carvalho } \\
\text { (2008); Miranda (2004); De } \\
\text { Bettio e Martins (2004); } \\
\text { Longmire (2001) e Sá Filho e } \\
\text { Machado (2004) }\end{array}$ \\
\hline Usabilidade & $\begin{array}{l}\text { Relacionado à facilidade na navegação. Possibilita que } \\
\text { o OA seja utilizado com satisfação, eficácia e } \\
\text { eficiência. }\end{array}$ & $\begin{array}{l}\text { Simone }(2006) \text { e } \\
\text { Carvalho (2008) }\end{array}$ \\
\hline $\begin{array}{l}\text { Facilidade de } \\
\text { manutenção } \\
\text { Atualização } \\
\text { Versatilidade } \\
\text { Maneabilidade }\end{array}$ & $\begin{array}{l}\text { Os elementos que foram utilizados na construção do } \\
\text { objeto estão armazenados e organizados no editor ou } \\
\text { em um mesmo banco de informações, o que tornam as } \\
\text { alterações relativamente simples. }\end{array}$ & $\begin{array}{c}\text { IEEE/LTSC (2000); } \\
\text { De Bettio e Martins (2004) e } \\
\text { Torrão (2008) }\end{array}$ \\
\hline $\begin{array}{l}\text { Autocontido } \\
\text { Autônomo }\end{array}$ & $\begin{array}{l}\text { Restrito apenas a um computador não conectado à } \\
\text { rede de Internet. As conexões do objeto de } \\
\text { aprendizagem fazem referência somente a seus } \\
\text { próprios links, isto é, às referencias internas. }\end{array}$ & $\begin{array}{l}\text { Filatro }(2008) \text { e } \\
\text { Polsani }(2003)\end{array}$ \\
\hline Contido & $\begin{array}{l}\text { Quando o OA é utilizado com computador conectado } \\
\text { à Internet, possibilitando um acesso variado às } \\
\text { informações contidas em mídias eletrônicas ou links } \\
\text { externos a ele. }\end{array}$ & Filatro (2008) \\
\hline $\begin{array}{l}\text { Documentação } \\
\text { Facilidade de } \\
\text { Instalação }\end{array}$ & $\begin{array}{l}\text { Conjunto de atributos que evidenciam que a instrução } \\
\text { para a instalação e uso do OA está completa, é } \\
\text { consistente, legível e organizada. É a facilidade de os } \\
\text { usuários para localizarem e memorizarem informações } \\
\text { importantes para o seu uso. }\end{array}$ & $\begin{array}{l}\text { Campos e Campos (2001) e } \\
\text { LORI (versão 1.3) }\end{array}$ \\
\hline $\begin{array}{l}\text { Interação com a } \\
\text { interface }\end{array}$ & $\begin{array}{l}\text { Conjunto de atributos na interface que evidenciam a } \\
\text { existência de meios e recursos que facilitam a } \\
\text { interação do usuário com o } O A \text {. Também demonstra } \\
\text { quão proativo a configuração do sistema permite que } \\
\text { o usuário seja. }\end{array}$ & $\begin{array}{c}\text { LORI (versão 1.3); } \\
\text { Campos e Campos (2001) e } \\
\text { Silva (2012) }\end{array}$ \\
\hline
\end{tabular}

Fonte: Barbosa (2014) 
Por outro lado, para Menezes et al. (2006) há outra tendência a ser considerada na questão dos OA; seu caráter pedagógico. Portanto, consideraremos alinhado a Lima (2013), os aspectos pedagógicos como sendo um grupo de elementos que podem estar presentes nos OA para auxiliar o processo de ensino e aprendizagem, apoiando a produção de conhecimento no processo educativo dos alunos e professores. O tratamento pedagógico relacionado aos OA é reforçado ainda pelos argumentos de De Bettio e Martins (2004), os quais acreditam que os “objetos de aprendizado" são ferramentas facilitadoras e trazem como vantagem a melhora na qualidade do ensino.

Retomando as definições dadas em Wiley (2000) e LTSC (2000) acerca da conceituação de OA, percebe-se que a finalidade para a qual eles são desenvolvidos está diretamente ligada ao processo de ensino e aprendizagem. Logo, é importante destacar características que estão atreladas aos OA, quando estes recursos são tomados para compor o cenário educacional.

Ressaltamos que boa parte dos aspectos pedagógicos a serem mencionados nesta pesquisa foi obtida a partir de características de materiais didáticos ou softwares educacionais. Alguns desses autores também se fundamentaram no papel das tecnologias digitais de um modo geral, para descreverem os aspectos educacionais relativos aos OA.

Outras características que serão mencionadas são provenientes de questões ligadas aos princípios pedagógicos do design instrucional de cursos à distância. Essa ocorrência se justifica porque os OA, segundo Filatro (2008), são adotados como recursos e utilizados vastamente nessa modalidade de ensino. Entendemos que tais ressalvas são convenientes, pois, embora haja grande número de pesquisas sobre os $\mathrm{OA}$, não existem na mesma proporção estudos relacionados à questão pedagógica, como propomos neste artigo.

Na Tabela 2 a seguir, estão reunidas as características dos OA nos aspectos pedagógicos a que anunciamos. Tais atributos vêm acompanhados de uma breve definição e os principais autores que as assinalaram. 
Tabela 2 - Aspectos Pedagógicos dos Objetos de Aprendizagem

\begin{tabular}{|c|c|c|}
\hline \multicolumn{3}{|c|}{ Aspectos Pedagógicos Pesquisados } \\
\hline Característica & Definição & Autor/Fonte \\
\hline Reusabilidade/ Reutilização & $\begin{array}{l}\text { Poder ser integrado a um novo escopo pedagógico ou objetivo de aprendizagem. Também ser } \\
\text { utilizado para distintos tipos de alunos, quando se incorpora a ele componentes em múltiplas } \\
\text { aplicações e contextos; assim, é possível de ser adaptado. }\end{array}$ & $\begin{array}{l}\text { Tarouco et al. (2003) e } \\
\text { LORI (versão 1.3) apud Lima } \\
\text { et.al (2013) }\end{array}$ \\
\hline $\begin{array}{l}\text { Apresenta grau de } \\
\text { interatividade }\end{array}$ & $\begin{array}{l}\text { A possibilidade de um envolvimento do estudante com o conteúdo de alguma forma, podendo } \\
\text { ver, ouvir, ou responder a algum evento em resposta a uma interação com o objeto de } \\
\text { aprendizagem. Promove atividades abertas, com diversas maneiras de resolver problemas. } \\
\text { Alta interatividade: permite a descoberta imprevista e a descoberta de exploração livre. Média } \\
\text { interatividade: permite a descoberta guiada. Baixa interatividade: privilegia a aprendizagem de } \\
\text { recepção direcionada, a exposição indutiva e a exposição dedutiva. }\end{array}$ & $\begin{array}{c}\text { Carvalho (2008); } \\
\text { Silva (2012); } \\
\text { Tarouco e Mussoi (2011); } \\
\text { Belisário (2003); } \\
\text { Ramos e Santos (2006); } \\
\text { Campos e Campos (2001) e } \\
\text { HEODAR apud Lima et al. } \\
\text { (2013) }\end{array}$ \\
\hline Autonomia do usuário & $\begin{array}{l}\text { Exprime a obtenção da condição de independência pessoal e papel ativo ao estudante, ao dar } \\
\text { ênfase à interatividade e ao controle do aprendiz, encorajando-o à exploração e o envolvimento. }\end{array}$ & $\begin{array}{l}\text { Simone (2006); Carvalho (2008); } \\
\text { Loiselle (2002); } \\
\text { Ramos e Santos (2006) e } \\
\text { Ramal (2003) }\end{array}$ \\
\hline $\begin{array}{c}\text { Estimula aprendizagem } \\
\text { cooperativa/colaborativa }\end{array}$ & $\begin{array}{l}\text { Os seus usuários, incluindo o professor, precisarão trocar ideias e trabalhar coletivamente, seja } \\
\text { dupla ou grupo, para o desenvolvimento da atividade. }\end{array}$ & Ramos e Santos (2006) \\
\hline $\begin{array}{c}\text { Mobiliza ações } \\
\text { cognitivas/metacognitivas }\end{array}$ & $\begin{array}{l}\text { Cria condições que possibilitam uma reflexão sobre o que ele está fazendo. Refere-se às } \\
\text { demandas colocadas na memória do aprendiz, instigando-o à pesquisa, ao debate, ao confronto } \\
\text { de ideias, à verificação de hipóteses, à imaginação e tomada de decisão. }\end{array}$ & $\begin{array}{l}\text { Litto e Formiga (2012); } \\
\text { Ramos e Santos (2006) e } \\
\text { Tarouco (2003) }\end{array}$ \\
\hline $\begin{array}{l}\text { Pertinência ao programa } \\
\text { curricular }\end{array}$ & $\begin{array}{l}\text { Permite utilização em tarefas de ensino e aprendizagem de maneira consciente e coerente com } \\
\text { outras atividades e dinâmicas. Também pertinência do conteúdo em relação à área e subárea a } \\
\text { que ele se propõe, relevância dos assuntos, } \\
\text { clareza e concisão. }\end{array}$ & $\begin{array}{l}\text { Reategui e Boff (2010); } \\
\text { Ramal (2003); } \\
\text { Santos (2012); } \\
\text { Campos e Campos (2001) e } \\
\text { CCEAD/PUC-RIO (2009) }\end{array}$ \\
\hline Suscita motivação e desejo & $\begin{array}{l}\text { Capacidade de ser envolvente atrativo e contextualizado. Apresenta aspectos motivacionais, } \\
\text { amigável ao usuário, estimula o desejo de aprender, respeitando as individualidades. O OA } \\
\text { varia em tom, há sinais de humor ou novidade na apresentação dos conteúdos e a interação do } \\
\text { aluno com o OA tem consequências interessantes. Propõe desafios atingiveis, sem gerar } \\
\text { ansiedade. }\end{array}$ & $\begin{array}{l}\text { Ramos e Santos (2006); } \\
\text { Ramal (2003); } \\
\text { Campos e Campos (2001) e } \\
\text { LORI (versão 1.3) }\end{array}$ \\
\hline Autoconsistente & $\begin{array}{l}\text { Não depende de outro objeto de aprendizagem para fazer sentido, além de ser autoexplicativo. } \\
\text { Pode ser usado de forma autônoma para atingir determinados objetivos educacionais. }\end{array}$ & $\begin{array}{l}\text { Tavares et al. (2007) e } \\
\text { Gomes et al. (2004) }\end{array}$ \\
\hline $\begin{array}{c}\text { Temático } \\
\text { Contextualizado }\end{array}$ & $\begin{array}{l}\text { Possui atividades estruturadas em torno de um tema, fazendo referência ao universo dos alunos. } \\
\text { Apresenta uma forma de abordagem de cada conteúdo em função do público-alvo, incluindo } \\
\text { aspectos como linguagem e estilo dos exemplos concretos. }\end{array}$ & $\begin{array}{l}\text { Behar et al. (2009); } \\
\text { Ramos e Santos (2006) e } \\
\quad \text { Ramal (2003) }\end{array}$ \\
\hline Modularidade & $\begin{array}{l}\text { Apresentam-se em módulos independentes e não sequenciais. A modularidade faz parte de um } \\
\text { ambiente completo, podendo conter outros objetos de aprendizagem ou estar contido em um ou } \\
\text { mais cursos. }\end{array}$ & $\begin{array}{l}\text { Behar et al. (2009) } \\
\text { Gomes et al. (2004) }\end{array}$ \\
\hline Organização & $\begin{array}{l}\text { A organização dos conteúdos numa estrutura, que pode funcionar como uma âncora, um botão } \\
\text { Menu auxiliar ou uma árvore de navegação rápida. A estruturação dos conteúdos segundo uma } \\
\text { metodologia pedagógica pode ajudar na compreensão e aquisição do conhecimento. }\end{array}$ & Torrão (2008) \\
\hline Controle & $\begin{array}{l}\text { Capacidade de seguir a utilização e a interação do aluno com o conteúdo e a utilização dessa } \\
\text { informação para o formador e a entidade gestora da formação. }\end{array}$ & Carvalho (2008); \\
\hline $\begin{array}{l}\text { Suporte para os objetivos da } \\
\text { aprendizagem }\end{array}$ & $\begin{array}{l}\text { Pró-atividade que assegura que um OA sempre atuará de forma a satisfazer os seus objetivos. } \\
\text { Possibilidade de ser combinado de acordo com os objetivos a serem alcançados. Factível: que } \\
\text { pode ser alcançado; esclarece o que se espera que seja aprendido: o aluno deve ser consciente } \\
\text { do que ele tem que aprender. Coerente com os objetivos gerais: os objetivos específicos } \\
\text { devem ajudar a cumprir os objetivos gerais. }\end{array}$ & $\begin{array}{l}\text { Reategui e Boff (2010); } \\
\text { Gomes et al. (2004); } \\
\text { LORI (versão 1.3) e } \\
\text { HEODAR apud Lima et al. } \\
\text { (2013) }\end{array}$ \\
\hline Sociabilidade & $\begin{array}{l}\text { Habilidade de ser cooperativo com relação aos outros OA do ambiente. Também favorecer a } \\
\text { interdisciplinaridade de áreas através do conteúdo nele abordado. }\end{array}$ & $\begin{array}{l}\text { Gomes et.al (2004) e } \\
\text { CCEAD/PUC-RIO (2009) }\end{array}$ \\
\hline $\begin{array}{l}\text { Abordagem reflexivo-crítica } \\
\text { Ênfase na formação e no } \\
\text { desenvolvimento de } \\
\text { competências }\end{array}$ & $\begin{array}{l}\text { Desenvolvido com uma perspectiva que leve o aluno a refletir e a posicionar-se diante do que } \\
\text { aprende. Estimulam-no a desenvolver a capacidade de análise e a visão estratégica, } \\
\text { competências essenciais para a formação. }\end{array}$ & $\begin{array}{l}\text { Ramal (2003) e } \\
\text { Brasil (PCN) }\end{array}$ \\
\hline Usabilidade & $\begin{array}{l}\text { Atende um objetivo educacional, de fácil navegação. Apresenta ainda qualidade nos recursos de } \\
\text { ajuda da interface. }\end{array}$ & $\begin{array}{l}\text { Santos (2012); Lima et al. (2013) } \\
\text { e LORI (versão 1.3) }\end{array}$ \\
\hline Tempo de aprendizagem & $\begin{array}{l}\text { É o tempo de duração estimado para o desenvolvimento da unidade adequado ao tempo } \\
\text { disponibilizado ou determinado. }\end{array}$ & $\begin{array}{l}\text { HEODAR apud Lima et al. } \\
\text { (2013) }\end{array}$ \\
\hline $\begin{array}{l}\text { Ambiente educacional } \\
\text { Projeto para a } \\
\text { aprendizagem }\end{array}$ & $\begin{array}{l}\text { Deve permitir a identificação do ambiente educacional e do modelo de aprendizagem que ele } \\
\text { privilegia. Identificado pelo nivel de ensino, que por sua vez tem um nivel de dificuldade } \\
\text { compativel ao nível dos estudantes. }\end{array}$ & $\begin{array}{l}\text { Campos e Campos (2001) e } \\
\text { LORI (versão 1.3) }\end{array}$ \\
\hline $\begin{array}{c}\text { Qualidade da Informação } \\
\text { Precisão de conteúdo }\end{array}$ & Apresentar conteúdos corretos, fontes fidedignas, carga informacional compatível e pertinente. & $\begin{array}{c}\text { Campos e Campos (2001) } \\
\text { LORI (versão 1.3) }\end{array}$ \\
\hline Percurso pedagógico & $\begin{array}{l}\text { Sequencial: após realizar uma primeira atividade o aluno é direcionado automaticamente para a } \\
\text { atividade seguinte, e assim sucessivamente; } \\
\text { Redirecionado: Se um aluno não atingir resultados satisfatórios esperados, certa pontuação, por } \\
\text { exemplo, pode ser redirecionado para outras atividades sobre a mesma matéria até atingir o grau } \\
\text { de satisfação definido. } \\
\text { Adaptado: ligações para conteúdos que não estão contemplados no percurso definido, mas } \\
\text { podem interessar ao aluno porque complementam a sua aprendizagem. Permite uma } \\
\text { aprendizagem adaptada às necessidades do aluno e a um maior grau de liberdade na escolha do } \\
\text { que lhe interessa realmente. }\end{array}$ & Carvalho, (2008) \\
\hline
\end{tabular}

Fonte: Barbosa (2014) 


\section{Avaliação de um OA}

Avaliar os materiais educacionais, segundo Campos e Campos (2001) se faz necessário quando se pretende utilizá-los no processo de ensino e aprendizagem. Porém, isso não se restringe apenas a identificar os defeitos de funcionamento, mas, trata-se também de observar os atributos que evidenciam a conveniência e viabilidade de seu uso, facilidade de manipulação desse produto, orientações de instalação consistentes e legíveis, dentre outros.

Logo, é de fundamental importância aplicar uma metodologia adequada para essa avaliação. Além disso, envolver nesse processo avaliativo os usuários do material a ser avaliado, garante que certos fatores sejam considerados para qualificação desses recursos. Fernandes et. al. (2009) argumentam que avançar na testagem do OA produzido, na escola ou em um grupo selecionado de usuários, antes de publicá-los em repositórios, pode elucidar muitas percepções. Dentre elas, a observação de como a escola (ou professor) recebe e utiliza esses recursos digitais.

Em Silva (2011) é citado uma técnica de avaliação que solicita opiniões dos usuários. Segundo o autor, é bastante eficaz por fornecer um bom retorno do usuário, o qual expressa sua opinião sobre o produto analisado por meio de questionários e entrevistas.

Outro instrumento de avaliação também muito utilizado atualmente, principalmente nos Estados Unidos e Canadá é o Leaning Object Review Instrument (LORI), o qual foi desenvolvido pelo e-Learning Research and Assesment Network. Ele é específico para a avaliação de OA e explora os seguintes itens: qualidade do conteúdo, alinhamento de OA, feedback e adaptação, motivação, projeto de apresentação, usabilidade, acessibilidade, reusabilidade, aderência e padrões.

Tem-se ainda o recurso de avaliação de OA denominado Instrumento para a Avaliação da Qualidade de Objetos de Aprendizagem desenvolvido pela Coordenação Central de Educação a Distância da PUC-RIO (CCEAD/PUC-RIO (2009)/PUC-Rio) ${ }^{6}$. Ele foi amplamente utilizado pelas várias instituições nacionais participantes do edital 1/2007 para a produção de conteúdos educacionais digitais multimídia, lançado pelo Ministério da Educação, por meio da Secretaria de Educação a Distância.

O instrumento de avaliação denominado $\mathrm{HEODAR}^{7}$, segundo Lima et. al (2013) também foi desenvolvido com o objetivo de avaliar as variáveis tanto pedagógicas quanto técnicas dos OA. Os autores acrescentam que esse instrumento avalia mais variáveis do que o instrumento LORI, dividindo os aspectos que avalia em duas categorias: Psicopedagógico e Didático-curricular.

\footnotetext{
${ }^{6}$ CCEAD/PUC-RIO (2009) PUC-RIO. Disponível em <http://web.ccead.puc-rio.br/condigital/portal/>. Acesso em 29/03/15.

${ }^{7}$ Herramienta para la evaluación de objetos didácticos de aprendizaje reutilizables (HEODAR). Disponível em < http://docs.MOODLE.org/20/en/Heodar>. Acesso em 29/03/15.
} 
Além desses, o Núcleo de Tecnologia Digital Aplicada à Educação (NUTED) ${ }^{8}$ da Universidade Federal do Rio Grande do Sul também propõe um instrumento de avalição de OA. Segundo Lima et. al (2013), tal modelo se baseia no sistema MERLOT, uma vez que faz referência aos aspectos pedagógicos a partir de três grupos: qualidade do conteúdo, sua usabilidade e didática.

Os instrumentos aqui apresentados objetivam dar embasamento para a proposta que iremos desenvolver nesta pesquisa, principalmente quanto aos aspectos tecnológicos e pedagógicos.

\section{OA para educação financeira escolar}

A perspectiva de Educação Financeira Escolar que estamos utilizando nesse artigo foi formulada por Silva e Powell (2013) nos seguintes termos:

A Educação Financeira Escolar constitui-se de um conjunto de informações através do qual
os estudantes são introduzidos no universo do dinheiro e estimulados a produzir uma
compreensão sobre finanças e economia, através de um processo de ensino que os torne
aptos a analisar, fazer julgamentos fundamentados, tomar decisões e ter posições críticas
sobre questões financeiras que envolvam sua vida pessoal, familiar e da sociedade em que
vivem. (SILVA, POWELL, 2013)

Considerando essa perspectiva, a utilização dos recursos digitais OA na Educação Financeira Escolar tem como objetivo auxiliar de forma interativa e atrativa no processo educacional para a formação de estudantes que saibam analisar criticamente os temas atuais da sociedade de consumo. Bem como, permitir que esse aluno compreenda as noções básicas de finanças e economia e desenvolvam uma leitura crítica das informações financeiras presentes na sociedade. E ainda, que consigam assimilar os conhecimentos da matemática escolar e financeira para fundamentar a tomada de decisões em questões financeiras.

Tais recursos digitais, através de simuladores e animações podem possibilitar uma maior interação do aluno com os temas em questão. Consequentemente, incitar-lhes senso crítico e à tomadas de decisões conscientes, defendendo-se até mesmo das mazelas do mercado. Isto porque, a possibilidade de testar caminhos diferentes, de simular situações e perceber virtualmente como as relações evoluem, configuram-se mecanismos importantes e eficientes para o processo da educação financeira de cada estudante.

Segundo Santos e Amaral (2012), os OA despertam novas ideias, induzem os alunos a relacionarem conceitos e instigam à curiosidade e resolução de problemas. De acordo com estes autores, as atividades interativas e virtuais oferecem oportunidades de exploração de fenômenos científicos e conceitos muitas vezes inviáveis ou inexistentes nas escolas por questões econômicas e/ou de segurança.

\footnotetext{
8 Núcleo de Tecnologias Digital aplicado a Educação (NUTED). Disponível em < http://www.nuted.ufrgs.br/?page_id=79>. Acesso em 29/03/15.
} 
Nessa direção, apresentaremos alguns exemplos de AO para a Educação Financeira, cuja seleção se deu a partir de pesquisas nos Repositórios de Objetos de Aprendizagem (ROA).

O primeiro exemplo é uma animação que simula a compra de itens de aniversário, intitulada "Festa de Aniversário" 9 selecionado a partir do repositório do Núcleo de Educação Corporativa (NEC). A proposta deste OA é que o estudante compre itens para organizar uma festa de aniversário. Para realizá-la, o usuário terá uma lista composta de enfeites, bebidas, salgados e doces.

O software disponibiliza as lojas virtuais, em que o estudante poderá adquirir os produtos, os quais são listados por um personagem.

Figura 1 - Ilustração da página inicial do OA Festa de Aniversário

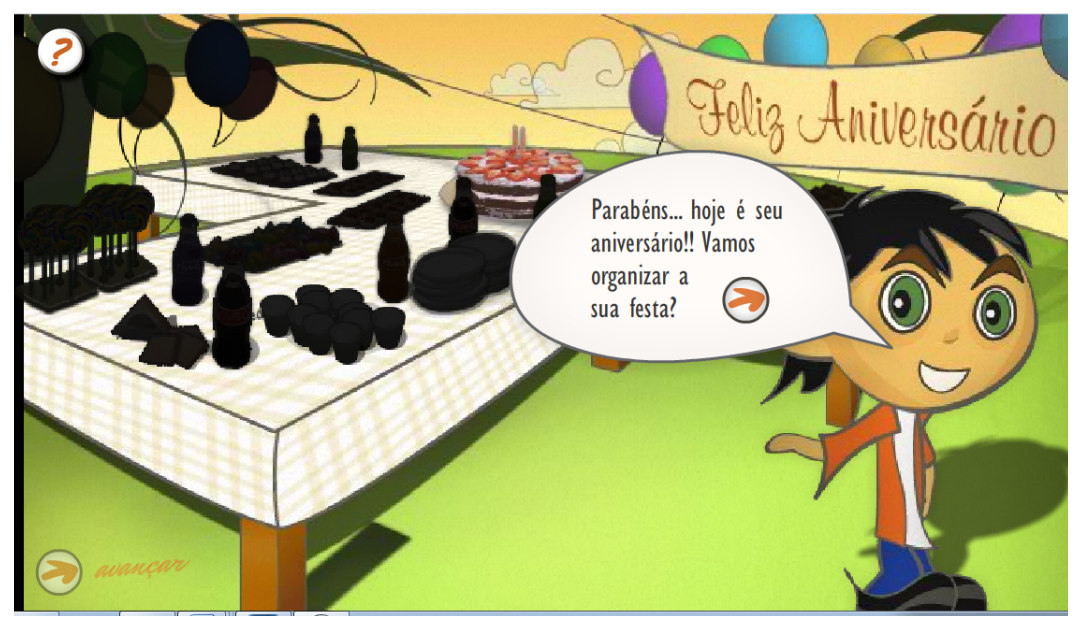

Fonte: Repositório RIVED (2015)

"Rickie o Hippie na Ecocasa"10 é o segundo exemplo de OA que apresentamos. O objetivo deste recurso é a de favorecer a aprendizagem do estudante a partir das observações e informações recebidas ao visitar uma casa ecologicamente correta. A tela inicial do OA está apresentada na figura 2.

Figura 2 - Tela inicial do OA Rickie o Hippie na Ecocasa

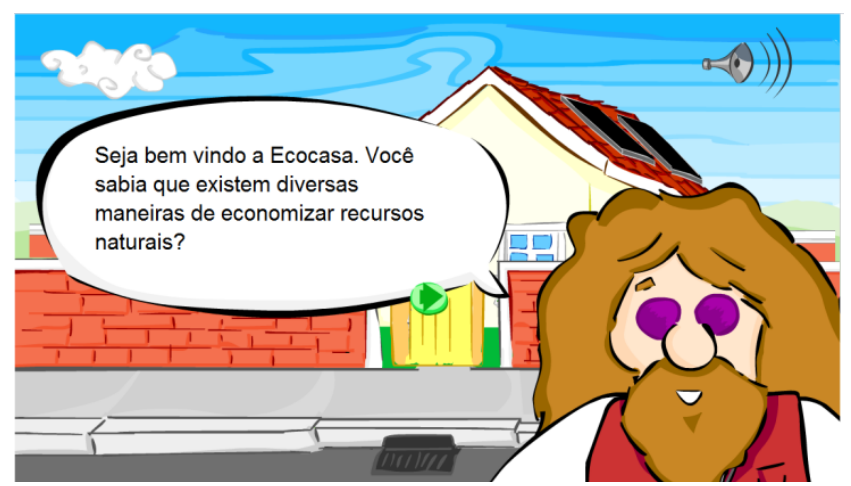

Fonte: NEC Prudente UNESP (2015)

\footnotetext{
${ }^{9}$ Disponível em: $<$ http://www.nec.fct.unesp.br/NEC/RIVED/Objetos.php>. Acesso em 29/03/15.

${ }^{10}$ Disponível em<www.nec.prudente.unesp.br>. Acesso em Acesso em 29/03/15.
} 
O terceiro exemplo de OA apresentado neste artigo, o qual relaciona educação financeira para estudantes, chama-se "Um dia de Compras" ${ }^{11}$. Essa atividade tem como objetivos explorar o conceito de unidades e medidas e estimular os aprendizes a administrar valores, a partir de uma lista de itens a serem comprados. A atividade também incentiva os estudantes a pesquisar antes de fazer compras, ao propor várias barracas de produtos com preços distintos e o aluno deve executar suas compras optando pelos produtos mais baratos. A tela inicial de apresentação dele está ilustrada na figura 3 .

Figura 3 - Tela inicial do OA "Um dia de Compras"

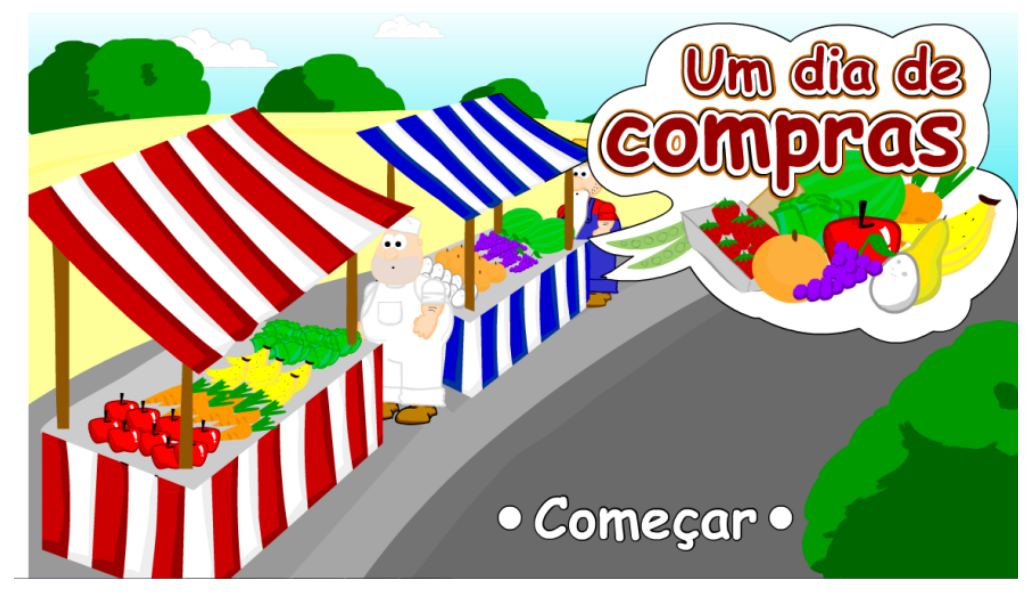

Fonte: NEC Prudente Unesp (2015)

Observamos que os objetivos propostos nos três exemplos de OA citados tratam do assunto educação financeira. Contudo, não temos informação se eles já foram aplicados em sala de aula e quais os resultados obtidos.

\section{Apresentação e análise dos resultados}

A partir da revisão bibliográfica que desenvolvemos, identificamos a importância das atribuições tecnológicas e pedagógicas dos OA. Compreendemos que essas atribuições são decisivas para que, ao serem introduzidos no contexto escolar, esses materiais se mostrem úteis para o processo de ensino e aprendizagem. Ela também foi essencial para compreendermos como os OA têm sido abordados por diversos teóricos da área.

Percebemos inicialmente que, boa parte dos artigos e trabalhos acadêmicos se limitavam a descrever esse recurso e focar apenas em suas características tecnológicas. E que, mais recentemente os OA têm sido abordados em relação ao seu uso prático e com foco nos aspectos pedagógicos, que os definem para finalidade didática.

\footnotetext{
${ }^{11}$ Disponível em <www.nec.prudente.unesp.br>. Acesso em 29/03/15.
} 
A partir da analise rigorosa da revisão bibliográfica é que, conseguimos organizar e estabelecer uma lista de aspectos tecnológicos e pedagógicos que serão utilizados na proposta de metodologia de avaliação de OA. Porém, conforme observamos no parágrafo anterior, é recente a elucidação e análise dos recursos pedagógicos nos OA e, desta forma, somos sabedores da necessidade contínua de pesquisas e estudos nesta área.

Da revisão bibliográfica resultaram os aspectos tecnológicos e pedagógicos dos objetos de aprendizagem, exibidos nas tabelas 3 e 4, respectivamente. Intencionamos discutir e justificar aqui como eles foram reagrupados em categorias para compor a proposta de metodologia de avaliação de OA.

A descrição dos resultados da pesquisa dos aspectos tecnológicos e pedagógicos dos OA através de categorias foi baseada nos trabalhos dos autores Campos e Campos (2001) e Lima et. al (2013). Esses autores expressaram ser essa uma maneira de compreender e refletir sobre os aspectos tecnológicos e pedagógicos dos $\mathrm{OA}$.

Campos e Campos (2001) apresentam um conjunto de atributos que evidenciam a conveniência e viabilidade de utilização dos softwares em situações educacionais. Os autores fazem uma abordagem significativa em relação aos aspectos tecnológicos de um software educacional, incluindo as principais dimensões relacionadas a esses aspectos.

Mediante isso, utilizamos a abordagem desses autores e adaptamos em aspectos tecnológicos para OA. Assim, as categorias dos aspectos tecnológicos se constituíram da seguinte maneira: Operacionalidade, que se refere às questões de portabilidade. Estrutura, que engloba as características da interface e a categoria Facilidade de uso, que se refere aos aspectos que auxiliam a manipulação do objeto.

A justificativa para que tomássemos um conjunto de atributos relacionados a software educacional se deve ao fato desses aplicativos também virem a ser OA.

Tabela 3 - Categorias dos Aspectos Tecnológicos

\begin{tabular}{|c|c|c|c|c|c|c|}
\hline 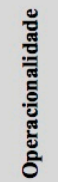 & $\begin{array}{ll}\text { - } & \text { Interoperabilid } \\
\text { - } & \text { Portabilidade } \\
\text { - } & \text { Adabilidadabilidad } \\
\text { - } & \text { Flexibilidade } \\
\text { - Reutilização o }\end{array}$ & usabilidade & $\begin{array}{ll}\text { - } & \text { Acessi } \\
& \text { arquite } \\
\text { - } & \text { Escala } \\
\text { - } & \text { Indexa } \\
\text { - } & \text { Classi }\end{array}$ & $\begin{array}{l}\text { dade: barreiras } \\
\text { icas. } \\
\text { lade } \\
\text { ão }\end{array}$ & $\dot{\bullet}$ & $\begin{array}{l}\text { Metadados } \\
\text { Recuperabilidade } \\
\text { Padronização } \\
\text { Granularidade } \\
\text { Customização }\end{array}$ \\
\hline 营 & $\begin{array}{l}\text { - Acessibilidade } \\
\text { - Interação com }\end{array}$ & $\begin{array}{l}\text { nimizar barre } \\
\text { terface }\end{array}$ & ras arquitetôr & & & \\
\hline 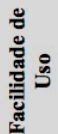 & $\begin{array}{l}\text { - Usabilidade } \\
\text { - Facilidade de } \\
\text { manutenção }\end{array}$ & $\begin{array}{ll}\text { - } & \text { Atuali } \\
\text { - } & \text { Versa } \\
\text { - } & \text { Mane } \\
\text { - } & \text { Nível }\end{array}$ & $\begin{array}{l}\text { ação } \\
\text { lidade } \\
\text { bilidade } \\
\text { le agregação }\end{array}$ & $\begin{array}{ll}\text { - } & \text { Autocon } \\
\text { - } & \text { Autônom } \\
\text { Contido }\end{array}$ & & $\begin{array}{l}\text { - Guias, orientações e } \\
\text { - Ajuda } \\
\text { - Facilidade de Instalação }\end{array}$ \\
\hline
\end{tabular}

Fonte: BARBOSA (2014) 
Já as categorias constituídas sobre os aspectos pedagógicos são: Psicopedagógico, Currículo, Conteúdo, Didática e Feedback/Adaptação. Elas estão esboçadas na Tabela 4 e foram extraídas dos estudos de Lima et. al (2013). Esses autores conduzem uma reflexão para justificar cada uma dessas categorias e traremos essas ideias abordadas por eles para assim entendermos como elas se estabeleceram.

Tabela 4 - Categorias dos Aspectos Pedagógicos

\begin{tabular}{|c|c|}
\hline & Aspectos Pedagógicos definidos na Revisão Bibliográfica \\
\hline 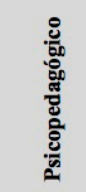 & $\begin{array}{l}\text { - Apresenta grau de Interatividade } \\
\text { - } \quad \text { Autonomia do usuário } \\
\text { - } \quad \text { Mobiliza ações cognitivas/metacognitivas } \\
\text { - } \quad \text { Suscita motivação e desejo } \\
\text { - Abordagem reflexivo-crítica }\end{array}$ \\
\hline 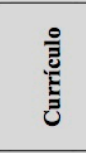 & $\begin{array}{ll}\text { - } & \text { Reusabilidade } \\
\text { - } & \text { Concepção epistemológica } \\
\text { - } & \text { Pertinência ao programa curricular } \\
\text { - } & \text { Projeto para a aprendizagem } \\
\end{array}$ \\
\hline ن̊ & $\begin{array}{l}\text { - Temático e Contextualizado } \\
\text { - } \quad \text { Qualidade da Informação } \\
\text { - Precisão de conteúdo }\end{array}$ \\
\hline 总 & $\begin{array}{ll}\text { - } & \text { Organização } \\
\text { - } & \text { Suporte para os objetivos da aprendizagem } \\
\text { - } & \text { Percurso pedagógico } \\
\text { - } & \text { Tentrole } \\
\end{array}$ \\
\hline 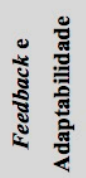 & $\begin{array}{ll}\text { - } & \text { Autoconsistente } \\
\text { - } & \text { Autonomia do OA } \\
\text { - } & \text { Sociabilidade } \\
\text { - } & \text { Usabilidade } \\
\text { - } & \text { Modularidade }\end{array}$ \\
\hline
\end{tabular}

Fonte: Barbosa (2014)

A categoria Psicopedagógico engloba os aspectos dos OA relativos aos benefícios pedagógicos, que podem propiciar ao aprendiz, tais como captar a atenção, oferecer informações suficientes para o entendimento do conteúdo e promover atividades diversas, tais como atividades abertas para reflexão.

A categoria Currículo, segundo Lima et al. (2013), envolve aspectos relacionados a esclarecer se o OA é pertinente a um programa curricular. E, detalhes do conteúdo dos OA são reunidos na categoria Conteúdo. Nela também estão englobados os aspectos que permitem identificar e analisar características quanto à relevância do assunto, clareza e concisão dos mesmos. Também a atualização e referência das informações apresentadas no OA.

Lima et al. (2013) englobam os aspectos para analisar se os conteúdos são retomados progressivamente, se pré-requisitos são estabelecidos e se há organização da atividade na categoria Didática. Também, se a atividade do OA favorece a interdisciplinaridade e os assuntos seguem uma ordem lógica, do geral para os conceitos mais específicos. 
Por fim, na categoria Feedback/Adaptabilidade, os autores citados reúnem os aspectos pedagógicos, que verificam se o OA adapta-se às mensagens instrutivas, se por meio dele é possível construir, junto com o aluno, uma aprendizagem fundamentada em suas respostas. Ainda, se há possibilidade de promover atividades abertas, que exploram outros $\mathrm{OA}$ ou pesquisas na internet. $\mathrm{E}$ com isso, proporcionando realimentação de informações e correção de erros.

A partir dos resultados que acabamos de descrever chegamos a dois cheklists, o qual denominamos de Metodologia para Avaliação de OA (MESA). O primeiro corresponde aos aspectos tecnológicos (Tabela 5) e o segundo aos pedagógicos (Tabela 6).

A utilização da metodologia MESA para análise dos aspectos tecnológicos e pedagógicos levam o avaliador (professor) a conhecer as características necessárias para um OA. Além disso, através da ocorrência ou não de determinado aspecto o professor decidirá sobre aqueles aspectos os quais considera e acredita serem mais relevantes para sua experiência com tal OA. As duas listas, embora extensas, são abrangentes e abordam os quesitos que um recurso educacional digital precisa contemplar.

A conclusão da avaliação ocorrerá com a contagem e soma dos aspectos que cada OA apresentou. E ainda assim, caberá ao professor o papel de julgar a relevância de tais ocorrências. 
Tabela 5 - Metodologia MESA - Aspectos Tecnológicos

\begin{tabular}{|c|c|c|}
\hline \multicolumn{3}{|c|}{$\begin{array}{l}\text { METODOLOGIA PARA SELEÇÃO E ANÁLISE DE OA - MESA } \\
\text { Aspectos Tecnológicos }\end{array}$} \\
\hline Característica & Definição & Observação \\
\hline $\begin{array}{l}\text { Interoperabilidade } \\
\text { Portabilidade } \\
\text { Durabilidade } \\
\text { Adaptabilidade } \\
\text { Flexibilidade }\end{array}$ & $\begin{array}{l}\text { A possibilidade de serem utilizados em diferentes ambientes } \\
\text { de ensino, plataformas, sistema operacional e navegador } \\
\text { web, não necessitando para isso, sofrer recodificação. É a } \\
\text { não obsolescência do OA quando a base tecnológica muda. }\end{array}$ & \\
\hline $\begin{array}{l}\text { Reutilização ou } \\
\text { Reusabilidade }\end{array}$ & $\begin{array}{l}\text { Capacidade de ser reaproveitado em diferentes contextos de } \\
\text { aprendizagem, sem necessidade de ser redesenhado de } \\
\text { modo a enquadrar-se no novo contexto. Varia de acordo } \\
\text { com a Granularidade do OA. }\end{array}$ & \\
\hline $\begin{array}{l}\text { Recuperabilidade } \\
\text { Acessibilidade: } \\
\text { disponibilidade }\end{array}$ & $\begin{array}{l}\text { Está ligado ao fato dos objetos de aprendizagem ser } \\
\text { identificados pelos "metadados", os quais os tornam } \\
\text { localizáveis, mesmo em lugares remotos. É a facilidade de } \\
\text { acesso pelos mecanismos de busca. }\end{array}$ & \\
\hline $\begin{array}{l}\text { Acessibilidade: } \\
\text { minimizar } \\
\text { barreiras } \\
\text { arquitetônicas }\end{array}$ & $\begin{array}{l}\text { Implica na possibilidade de utilização por pessoas com } \\
\text { necessidades especiais, decorrentes de limitações sensório- } \\
\text { motoras. }\end{array}$ & \\
\hline Escalabilidade & $\begin{array}{l}\text { A facilidade de poder ser utilizado com pequeno ou grande } \\
\text { número de usuários. }\end{array}$ & \\
\hline $\begin{array}{l}\text { Indexação } \\
\text { Classificação } \\
\text { Metadados } \\
\text { Padronização }\end{array}$ & $\begin{array}{l}\text { Permissão de atribuição de índices ou a catalogação, os } \\
\text { quais facilitarão a localização e identificação do objeto nos } \\
\text { mecanismos de busca. }\end{array}$ & \\
\hline $\begin{array}{l}\text { Granularidade } \\
\text { Nível de agregação } \\
\text { Customização }\end{array}$ & $\begin{array}{l}\text { É a capacidade do objeto de aprendizagem poder ser } \\
\text { agrupado e reagrupado em conjuntos maiores de conteúdo, } \\
\text { sendo usado em um curso ou outro da maneira que mais } \\
\text { convier. Isso dependerá da granularidade. Quanto mais } \\
\text { granular um OA for, maior sua capacidade de reutilização e } \\
\text { nível de agregação. Gerando, com isso maior customização } \\
\text { desses OA ao facilitar sua adaptação ou junção a outros OA. }\end{array}$ & \\
\hline Usabilidade & $\begin{array}{l}\text { Relacionado à facilidade na navegação. Possibilita que o } \\
\text { OA seja utilizado com satisfação, eficácia e eficiência. }\end{array}$ & \\
\hline $\begin{array}{l}\text { Facilidade de } \\
\text { manutenção } \\
\text { Atualização } \\
\text { Versatilidade } \\
\text { Maneabilidade }\end{array}$ & $\begin{array}{l}\text { Os elementos que foram utilizados na construção do objeto } \\
\text { estão armazenados e organizados no editor ou em um } \\
\text { mesmo banco de informações, o que tornam as alterações } \\
\text { relativamente simples. }\end{array}$ & \\
\hline $\begin{array}{l}\text { Autocontido } \\
\text { Autônomo }\end{array}$ & $\begin{array}{l}\text { Restrito apenas a um computador não conectado à rede de } \\
\text { Internet. As conexões do objeto de aprendizagem fazem } \\
\text { referência somente a seus próprios links, isto é, às } \\
\text { referencias internas. }\end{array}$ & \\
\hline Contido & $\begin{array}{l}\text { Quando o OA é utilizado com computador conectado à } \\
\text { Internet, possibilitando um acesso variado às informações } \\
\text { contidas em mídias eletrônicas ou links externos a ele. }\end{array}$ & \\
\hline $\begin{array}{c}\text { Documentação } \\
\text { Facilidade de } \\
\text { Instalação }\end{array}$ & $\begin{array}{l}\text { Conjunto de atributos que evidenciam que a instrução para a } \\
\text { instalação e uso do OA está completa, é consistente, legível } \\
\text { e organizada. É a facilidade de os usuários para localizarem } \\
\text { e memorizarem informações importantes para o seu uso. }\end{array}$ & \\
\hline $\begin{array}{l}\text { Interação com a } \\
\text { interface }\end{array}$ & $\begin{array}{l}\text { Conjunto de atributos na interface que evidenciam a } \\
\text { existência de meios e recursos que facilitam a interação do } \\
\text { usuário com o } O A \text {. Também demonstra quão proativo a } \\
\text { configuração do sistema permite que o usuário seja. }\end{array}$ & \\
\hline
\end{tabular}

Fonte: Barbosa (2014) 
Tabela 6 - Metodologia MESA - Aspectos Pedagógicos

\begin{tabular}{|c|c|c|}
\hline \multicolumn{3}{|c|}{ LOGIA PARA SELEÇÃO E ANÁLISE DE OA- } \\
\hline Característica & Definição & Observação: \\
\hline $\begin{array}{l}\text { Reusabilidade/ } \\
\text { Reutilização }\end{array}$ & $\begin{array}{l}\text { Poder ser integrado a um novo escopo pedagógico } \\
\text { ou objetivo de aprendizagem. Também ser } \\
\text { utilizado para distintos tipos de alunos, quando se } \\
\text { incorpora a ele componentes em múltiplas } \\
\text { aplicações e contextos; assim, é possível de ser } \\
\text { adaptado. }\end{array}$ & \\
\hline $\begin{array}{l}\text { Apresenta grau de } \\
\text { interatividade }\end{array}$ & $\begin{array}{l}\text { A possibilidade de um envolvimento do estudante } \\
\text { com o conteúdo de alguma forma, podendo ver, } \\
\text { ouvir, ou responder a algum evento em resposta a } \\
\text { uma interação com o objeto de aprendizagem. } \\
\text { Promove atividades abertas, com diversas } \\
\text { maneiras de resolver problemas. } \\
\text { Alta interatividade: permite a descoberta } \\
\text { imprevista e a descoberta de exploração livre. } \\
\text { Média interatividade: permite a descoberta guiada. } \\
\text { Baixa interatividade: privilegia a aprendizagem de } \\
\text { recepção direcionada, a exposição indutiva e a } \\
\text { exposição dedutiva. }\end{array}$ & \\
\hline Autonomia do usuário & $\begin{array}{l}\text { Exprime a obtenção da condição de independência } \\
\text { pessoal e papel ativo ao estudante, ao dar ênfase à } \\
\text { interatividade e ao controle do aprendiz, } \\
\text { encorajando-o à exploração e o envolvimento. }\end{array}$ & \\
\hline $\begin{array}{l}\text { Estimula aprendizagem } \\
\text { cooperativa/colaborativa }\end{array}$ & $\begin{array}{l}\text { Os seus usuários, incluindo o professor, precisarão } \\
\text { trocar ideias e trabalhar coletivamente, seja dupla } \\
\text { ou grupo, para o desenvolvimento da atividade. }\end{array}$ & \\
\hline $\begin{array}{c}\text { Mobiliza ações } \\
\text { cognitivas/metacognitivas }\end{array}$ & $\begin{array}{l}\text { Cria condições que possibilitam uma reflexão } \\
\text { sobre o que ele está fazendo. Refere-se às } \\
\text { demandas colocadas na memória do aprendiz, } \\
\text { instigando-o à pesquisa, ao debate, ao confronto de } \\
\text { ideias, à verificação de hipóteses, à imaginação e } \\
\text { tomada de decisão. }\end{array}$ & \\
\hline $\begin{array}{c}\text { Pertinência ao programa } \\
\text { curricular }\end{array}$ & $\begin{array}{l}\text { Permite utilização em tarefas de ensino e } \\
\text { aprendizagem de maneira consciente e coerente } \\
\text { com outras atividades e dinâmicas. Também } \\
\text { pertinência do conteúdo em relação à área e } \\
\text { subárea a que ele se propõe, relevância dos } \\
\text { assuntos, } \\
\text { clareza e concisão. }\end{array}$ & \\
\hline Suscita motivação e desejo & $\begin{array}{l}\text { Capacidade de ser envolvente atrativo e } \\
\text { contextualizado. } \\
\text { motivacionais, amigável ao usuário, estimula o } \\
\text { desejo de aprender, respeitando as } \\
\text { individualidades. O OA varia em tom, há sinais de } \\
\text { humor ou novidade na apresentação dos conteúdos } \\
\text { e a interação do aluno com o OA tem } \\
\text { consequências interessantes. Propõe desafios } \\
\text { atingíveis, sem gerar ansiedade. }\end{array}$ & \\
\hline Autoconsistente & $\begin{array}{l}\text { Não depende de outro objeto de aprendizagem para } \\
\text { fazer sentido, além de ser autoexplicativo. Pode ser } \\
\text { usado de forma autônoma para atingir } \\
\text { determinados objetivos educacionais. }\end{array}$ & \\
\hline $\begin{array}{c}\text { Temático } \\
\text { Contextualizado }\end{array}$ & $\begin{array}{l}\text { Possui atividades estruturadas em torno de um } \\
\text { tema, fazendo referência ao universo dos alunos. } \\
\text { Apresenta uma forma de abordagem de cada } \\
\text { conteúdo em função do público-alvo, incluindo } \\
\text { aspectos como linguagem e estilo dos exemplos } \\
\text { concretos. }\end{array}$ & \\
\hline Modularidade & $\begin{array}{l}\text { Apresentam-se em módulos independentes e não } \\
\text { sequenciais. A modularidade faz parte de um } \\
\text { ambiente completo, podendo conter outros objetos } \\
\text { de aprendizagem ou estar contido em um ou mais } \\
\text { cursos. }\end{array}$ & \\
\hline
\end{tabular}




\begin{tabular}{|c|c|}
\hline Organização & $\begin{array}{l}\text { A organização dos conteúdos numa estrutura, que } \\
\text { pode funcionar como uma âncora, um botão Menu } \\
\text { auxiliar ou uma árvore de navegação rápida. A } \\
\text { estruturação dos conteúdos segundo uma } \\
\text { metodologia pedagógica pode ajudar na } \\
\text { compreensão e aquisição do conhecimento. }\end{array}$ \\
\hline Controle & $\begin{array}{l}\text { Capacidade de seguir a utilização e a interação do } \\
\text { aluno com o conteúdo e a utilização dessa } \\
\text { informação para o formador e a entidade gestora } \\
\text { da formação. }\end{array}$ \\
\hline $\begin{array}{l}\text { Suporte para os objetivos } \\
\text { da aprendizagem }\end{array}$ & $\begin{array}{l}\text { Pró-atividade que assegura que um OA sempre } \\
\text { atuará de forma a satisfazer os seus objetivos. } \\
\text { Possibilidade de ser combinado de acordo com os } \\
\text { objetivos a serem alcançados. Factível: que pode } \\
\text { ser alcançado; esclarece o que se espera que seja } \\
\text { aprendido: o aluno deve ser consciente do que ele } \\
\text { tem que aprender. Coerente com os objetivos } \\
\text { gerais: os objetivos específicos devem ajudar a } \\
\text { cumprir os objetivos gerais. }\end{array}$ \\
\hline Sociabilidade & $\begin{array}{l}\text { Habilidade de ser cooperativo com relação aos } \\
\text { outros OA do ambiente. Também favorecer a } \\
\text { interdisciplinaridade de áreas através do conteúdo } \\
\text { nele abordado. }\end{array}$ \\
\hline $\begin{array}{c}\text { Abordagem reflexivo- } \\
\text { crítica } \\
\text { Ênfase na formação e no } \\
\text { desenvolvimento de } \\
\text { competências }\end{array}$ & $\begin{array}{l}\text { Desenvolvido com uma perspectiva que leve o } \\
\text { aluno a refletir e a posicionar-se diante do que } \\
\text { aprende. Estimulam-no a desenvolver a capacidade } \\
\text { de análise e a visão estratégica, competências } \\
\text { essenciais para a formação. }\end{array}$ \\
\hline Usabilidade & $\begin{array}{l}\text { Atende um objetivo educacional, de fácil } \\
\text { navegação. Apresenta ainda qualidade nos recursos } \\
\text { de ajuda da interface. }\end{array}$ \\
\hline Tempo de aprendizagem & $\begin{array}{l}\text { É o tempo de duração estimado para o } \\
\text { desenvolvimento da unidade adequado ao tempo } \\
\text { disponibilizado ou determinado. }\end{array}$ \\
\hline $\begin{array}{l}\text { Ambiente educacional } \\
\text { Projeto para a } \\
\text { aprendizagem }\end{array}$ & $\begin{array}{l}\text { Deve permitir a identificação do ambiente } \\
\text { educacional e do modelo de aprendizagem que ele } \\
\text { privilegia. Identificado pelo nível de ensino, que } \\
\text { por sua vez tem um nível de dificuldade } \\
\text { compatível ao nível dos estudantes. }\end{array}$ \\
\hline $\begin{array}{l}\text { Qualidade da Informação } \\
\text { Precisão de conteúdo }\end{array}$ & $\begin{array}{l}\text { Apresentar conteúdos corretos, fontes fidedignas, } \\
\text { carga informacional compatível e pertinente. }\end{array}$ \\
\hline Percurso pedagógico & $\begin{array}{l}\text { Sequencial: } \text { após realizar uma primeira atividade o } \\
\text { aluno é direcionado automaticamente para a } \\
\text { atividade seguinte, e assim sucessivamente; } \\
\text { Redirecionado: Se um aluno não atingir resultados } \\
\text { satisfatórios esperados, certa pontuação, por } \\
\text { exemplo, pode ser redirecionado para outras } \\
\text { atividades sobre a mesma matéria até atingir o grau } \\
\text { de satisfação definido. } \\
\text { Adaptado: ligações para conteúdo que não estão } \\
\text { contemplados no percurso definido, mas podem } \\
\text { interessar ao aluno porque complementam a sua } \\
\text { aprendizagem. Permite uma aprendizagem } \\
\text { adaptada às necessidades do aluno e a um maior } \\
\text { grau de liberdade na escolha do que lhe interessa } \\
\text { realmente. }\end{array}$ \\
\hline
\end{tabular}

Fonte: Barbosa (2014)

\section{Considerações finais}

A utilização de recursos educacionais digitais, especificamente os OA, para a Educação Matemática não é algo novo. Porém, ainda suscita discussões e pesquisas, principalmente quando da formação docente, para que, sua utilização por esses profissionais seja feita de forma equânime na sala de aula.

Nossa pesquisa teve como objetivo a investigação sobre a utilização dos OA na especificidade do ensino da Educação Financeira Escolar . A trajetória dessa pesquisa, nos 
proporcionou vários entendimentos e direcionamentos, alguns reflexivos para nós pesquisadores e outros, de orientação para os professores que fazem ou farão uso dos OA como recurso educacional.

A falta de unanimidade na definição do conceito de OA e a pluralidade dos aspectos que os caracterizam, fizeram com que aprofundássemos as leituras e análises destes recursos e com isso, resultou num referencial teórico amplo e consistente, porém, reflexivo e desafiador.

O uso dos OA na educação financeira escolar, objetiva propor um processo educacional interativo e atrativo para a formação de um cidadão que saiba analisar criticamente os temas atuais da sociedade de consumo. Desta forma, busca despertar nos alunos novas ideias, conduzi-los a relacionarem conceitos e instigam à curiosidade e resolução de problemas, pois as atividades interativas e virtuais oferecem oportunidades de exploração e simulação de situações reais em espaços virtuais.

Detectamos que nas buscas realizadas nos Repositórios de Objetos de Aprendizagem (ROA), encontramos um número reduzido de OA específicos para a educação financeira. Percebemos ainda, alguns catalogados de forma imprópria, ou seja, informando em seus metadados que pertenciam à área da educação financeira, porém ao analisarmos, resumiam-se apenas em explicações sobre conceitos e operações matemáticas, sem um aprofundamento crítico e aplicado à real proposta da educação financeira. Com isso, dificultando a utilização desses recursos digitais pelos professores.

Outra dificuldade que os professores podem encontrar quando analisar um OA, está em como definir se um OA pode ou não, ser considerado um recurso educacional no ensino da educação financeira. Esta definição está contemplada na presença simultânea dos aspectos tecnológicos e pedagógicos e, é definida no ato do planejamento e desenvolvimento do recurso digital. E, dependendo do perfil do desenvolvedor, pode-se favorecer mais um aspecto do que outro, podendo comprometer a função didática do OA.

Para auxiliar os professores e minimizar as dificuldades, esta pesquisa aponta como resultado uma Metodologia de Avaliação de OA (MESA) que reúne a partir de fundamentação científica, os aspectos tecnológicos e pedagógicos necessários para que os OA sejam considerados recursos educacionais digitais adequados e, possam ser usados como ferramentas no auxílio do processo de ensino e aprendizagem da educação financeira escolar.

A utilização da metodologia MESA para análise dos aspectos tecnológicos e pedagógicos leva o professor a conhecer as características necessárias para um OA. Além disso, através da ocorrência ou não de determinado aspecto o professor decidirá sobre aqueles aspectos os quais considera serem mais relevantes para sua experiência com tal OA. 
A MESA é uma metodologia autoexplicativa que pode ser utilizada por professores que possuam pouco ou nenhum conhecimento específicos sobre a tecnologia de OA, porém, tenham a pré-disposição em inovar no seu processo educacional.

Sabemos que o ensino da Educação Financeira Escolar não depende somente da utilização de recursos educacionais digitais, porém, acreditamos que os OA podem auxiliar de forma significativa na construção de conhecimentos para a formação dos estudantes.

\section{Referências}

BARBOSA. G.. Objetos de aprendizagem como recurso educacional digital para educação financeira: análise e avaliação. Dissertação de Mestrado - UFJF. Juiz de Fora. 2014.

CAMPOS, G. H. B.; CAMPOS, F. C. A.. Qualidade de Software Educacional. In Qualidade de software: Teoria e Prática. Ed. Campinas: Makron, 2001.

De BETTIO, R. W., MARTINS, A.. Objetos de aprendizado: um novo modelo direcionado ao ensino a distância. Congresso Internacional de Educação a Distância. 2004. Disponível em $<$ http://www.abed.org.br/congresso2002/trabalhos/texto42.htm>. Acesso em 26 set de 2013.

FERNANDES, A. C.; FREIRE, R. S.; SOUSA, M. F; MEDEIROS, M. D.; CASTRO Filho, J. A. Modelo para Qualidade de Objetos de Aprendizagem: da sua concepção ao uso em sala de aula. In Simpósio Brasileiro de Informática na Educação, 2009.

FILATRO, A. Design Instrucional: na prática. São Paulo: Pearson Education do Brasil, 2008.

HARMAN, K; KOOHANG, A. (Ed.). Learning objects: standards, metadata, repositories, and LCMS. Informing Science, 2007.

JESUS, A; GOMES, M. J; CRUZ, A.. Objetos de aprendizagem: uma proposta de design pedagógico. In II Congresso Internacional TIC e Educação, 2012.

KRÄMER, B. J.; SCHMIDT, H. W.. Components and tools for on-line education. European Journal of Education, 36. 2001.

L'ALLIER, J. J. Frame of Reference: NETg's Map to the Products, Their Structure and Core Beliefs. 1997. NetG. Disponível em <http://www.netg.com/research/whitepapers/ frameref.asp>. Acesso em 27 mar de 2013.

LIMA, L. A. F.; ALONSO, K. M.; MACIEL, C.. Análise da Qualidade em Objetos de Aprendizagem: reflexão sobre aspectos pedagógicos. In Anais dos Workshops do Congresso Brasileiro de Informática na Educação. 2013.

LTSC. Learning technology standards committee website. 2000. Disponível em $<$ http://ltsc.ieee.org/>. Acesso em 03 set de 2014.

MACEDO, C. M. S.. Diretrizes para Criação de Objetos de Aprendizagem Acessíveis. Tese de Doutorado. Programa de Pós-Graduação em Engenharia e Gestão do Conhecimento. Universidade Federal de Santa Catarina, Florianópolis. 2010. 
MENEZES, C. S.; LIRA, A. F.; FERRETTI C.; LINDNER E. L.. ODAI - Objetos Digitais para Aprendizagem Interacionista. In Anais do Simpósio Brasileiro de Informática na Educação. p.587-596, 2006.

OCDE. Recommendation on principles and good practices for financial education and a wareness. 2005. Disponível em <http://www.oecd.org/finance/financialeducation/35108 560.pdf>. Acesso em 29 mar. de 2015.

PORTER, D.. Object Lessons from the Web: Implications for Instructional Development. 2001. Disponível em < http://www.academia.edu/8332384/Object_Lessons_

from_the_Web_Implications_for_Instructional_Development/>. Acesso em 29 mar de 2015.

SANTOS, M. E. K. L.; AMARAL, L. H.. Avaliação de objetos virtuais de aprendizagem no ensino de matemática. Revista de Ensino de Ciências e Matemática, v. 3, n. 2, 2012.

SILVA, W. W.. Caracterização de deficiências de objetos de aprendizagem por meio dede avaliação de suas interfaces. Monografia de Graduação. Curso Ciência da Computação. Universidade Federal de Lavras, Lavras. 2011.

SILVA, A. M.; POWELL, A. B.. Um Programa de Educação Financeira para a Matemática Escolar da Educação Básica. In: Encontro Nacional de Educação Matemática. Curitiba. 2013.

TAROUCO, L. M. R.. Avaliação de Objetos de Aprendizagem. CINTED/UFRGS, 2012. Disponível em $<$ http://penta2.ufrgs.br/edu/objetosaprendizagem/sld001.htm>. Acesso em 29 mar de 2015.

WILEY, D. A.. Connecting learning objects to instructional design theory: A definition, a metaphor, and a taxonomy. 2000. Disponível em $<$ http://reusability.org/read/>. Acesso em $29 \mathrm{de}$ mar de 2015.

WILEY, D. A.. Impediments to Learning Object Reuse and Openness as a Potential Solution. Revista Brasileira de Informática na Educação, Volume 17, Número 3, 2009. 